\title{
Ridership and Human Mobility of Metro System Under the Typhoon Weather Event: A Case Study in Fuzhou, China
}

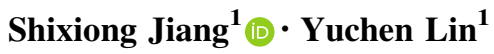

Received: 11 October 2021/Revised: 21 November 2021/Accepted: 14 December 2021/Published online: 11 February 2022

(C) The Author(s) 2022

\begin{abstract}
Extreme weather events, such as typhoon and hurricane, have characteristics of high uncertainty, large destructiveness, and extensiveness, which threat the daily life and cause apparent perturbations to human mobility. In order to investigate the perturbation on human mobility, this study collects the metro transaction data before and during a typhoon weather event in Fuzhou, China, to conduct analyses. The ridership before and during the typhoon weather event is innovatively compared at system, station and origin-destination level. Besides, it is of novelty to examine the travel time distribution of metro trips in the normal and perturbed state by comparing three candidate models with the Akaike information criterion method. Results validate that the typhoon weather event severely influences the ridership at system, station, and origin-destination level, with various degrees. There is also significant impact on the relative total traveled stations from the typhoon weather event, especially for leisure trips. Moreover, the travel time of metro trips follows the gamma distribution in both the normal state and the perturbed state with different magnitudes. It is found that both the number of traveled stations and travel time are lower in the typhoon state when compared to those in the normal state. In general, this study can provide some helps to assist the metro management under extreme weather events.
\end{abstract}

Shixiong Jiang

sxjiang@fzu.edu.cn

1 College of Computer and Data Science, Fuzhou University, Fuzhou 350116, China

Communicated by Xuesong Zhou.
Keywords Human mobility - Metro ridership - Travel time $\cdot$ Traveled stations $\cdot$ Typhoon weather

\section{Introduction}

Natural disasters, such as typhoon and hurricane, can affect travels of human being seriously. In the urban area, the densities of building and population are pretty high, and they are still increasing now. As a result, transportation is an indispensable part in urban lives and most citizens travel every day. However, transportation is an activity which is strictly linked with weather conditions and can be seriously influenced by natural disasters [1]. Thus, it is important to explore the human mobility perturbation resulted from the natural disasters so as to improve the management of urban transportation under extreme weather events.

There are many researchers exploring the travel behavior changes resulted from weather conditions. Jain and Singh [2] investigated the influence of extreme weather conditions of high temperatures, low temperatures, precipitation, and thunderstorms on travel choices by travelers in Delhi. It is found that metro users are likely to change current patterns during rains or high temperature, and metro users with longer traveling distances tend to keep current travel pattern. With a negative binomial regression model, Ngo [3] suggested that bus ridership is more sensitive to extreme weather events in lower-income areas than the wealthier ones. Wang et al. [4] utilized Twitter geo-locations to investigate severe winter storms' effects on human mobility, and found that these storms perturb both displacements and gyration radii of individuals' mobility. Similarly, with smart card data and meteorological records from Shenzhen, China, Zhou et al. [1] build up the daily and hourly weather-transit ridership relationship 
at the system and station level. It is found that urban stations are more vulnerable to outdoor weather in regard to ridership and regular transit users are more resilient to adverse weather. Furthermore, Zhang et al. [5] quantitatively assessed human mobility perturbations during rainstorm and snowstorm from the perspective of total displacements of taxi and bus trips. Lin et al. [6] applied log-linear regression models to determine weather's impact on bikeshare trips in Beijing. What's more, Yang et al. [7] explored the influences of weather on the non-motorized transport usage and found that solar access, wind and snow are influential factors. Generally, non-motorized modes (walking, cycling) are more sensitive to weather conditions and the metro system is less vulnerable $[8,9]$.

Furthermore, some studies applied travel data to explore travel behavior changes under natural disasters, such as flooding, typhoon, hurricane, and earthquake. Some transportation data are applied to investigate the changes during the natural disasters. Abad and Fillone [10] validated that travel time has a significant difference between normal and flooding conditions in Metro Manila, Philippines. It is showed that flood characteristics influence travel behavior and road-based transit service users tend to change travel behavior more than rail-based ones. Furthermore, Abad et al. [11] claimed that adaptations to flooding are made to commuting behavior depending on passenger's commute and employment situation. In addition, Lyu et al. [12] combined the interval fuzzy analytic hierarchy process and fuzzy clustering analysis to evaluate the flood risk of metro systems in subsiding environments. During Typhoon Koppu, more than $80 \%$ of taxis in Hong Kong were not in operation, and the average customer-search time for drivers was very short [13]. With taxi ridership during Hurricanes Irene and Sandy in New York, Bian et al. [14] validated that the number of taxi trips start to decrease about 24 hours before the landfall of hurricane. Furthermore, the ridership in hurricane periods has a strong linear association with that in normal periods. The hurricane has the greatest influence on taxi ridership during weekend and at night, while the least influence on a weekday during the day. In another study with similar backgrounds, Zhu et al. [15] found that the recovery rate is lower for Sandy than that for Irene. Besides, it is found that road network has a higher resilience when compared to the metro network. During Typhoon Mangkhut, Chen et al. [16] found that urban flows reduce by $39 \%$ during the disruption in Shenzhen, China. Moreover, fundamental urban functions experience less disruption and recreational related trips are more severely affected. With investigation of 5 typhoons in Shenzhen, Zhou et al. [17] found that typhoon events can severely impact the distributions and recovery of metro ridership. Besides, stronger typhoons lead to a larger effect on resilience, and the continuous precipitation can result in a longer recovery time.

Besides, it is important to understand the human mobility, which has wide applications in many fields, such as urban planning [18, 19], transportation [20-22], and epidemic prevention [23-25]. Gonzalez et al. [26] analyzed the trajectory of mobile phones and indicated that human trajectory has a high temporal and spatial regularity. Kraemer et al. [22] constructed the global human movement model to validate that human mobility follows a power law. With the increase in travel distance, the frequency of human movement decreases. Besides, in different socio-demographic and environmental contexts, human movement patterns are different. Through the analysis of taxi trajectory data, Wang et al. [27] found that the displacement distribution tends to follow the exponential law, and the travel time can be approximately fitted by a lognormal distribution. Lin and Yao [28] proposed a model to explain the power-law distribution mechanism based on taxi data and verify the significant power-law distribution of people's moving behavior distance in the single-car situation. Based on origin-destination metric and the corresponding displacement, Jiang et al. [29] found that a gamma distribution can fit the displacement of metro trips. In addition, for air passengers, it is found that the time interval follows the truncated power law and the travel distance agrees with the negative binomial distribution [30].

The Twitter data have been used to explore the human mobility during the natural disasters. Wang and Taylor [31] found that human movements follow truncated power-law distributions during and after Hurricane Sandy. Besides, it is indicated that the center of mass and the radius of gyration of each individual's movements during perturbation states and steady states are highly correlated. A similar study confirmed that the radius, distance, and entropy of individuals decreased significantly after Sandy [32]. They also found that individuals in higher transportation diversity locations generally maintained a higher distance and radius one week after Sandy. During Hurricanes Matthew and Harvey, Ahmouda et al. [33] validated that displacements become shorter and areas of activity become smaller during hurricanes. Furthermore, Wang and Taylor [34, 35] explored human movements in different natural disasters. They found that human movements are significantly perturbed by typhoons with different magnitudes in different cases and follow power-law distribution. Wang and Taylor [36] indicated that the average sentiment levels decrease with the earthquake intensity increase, and similar levels of sentiment are likely to cluster in space. Overall, the impacts of natural disasters on ridership and human mobility are summarized in Table 1 . 
Table 1 Literature review about the impact of natural disasters on human mobility.

\begin{tabular}{|c|c|c|c|c|c|}
\hline Study & Data & Region & Event & Indicator & Finding \\
\hline$[13]$ & $\begin{array}{l}\text { GPS data } \\
\text { of taxi }\end{array}$ & $\begin{array}{l}\text { Hong } \\
\text { Kong }\end{array}$ & $\begin{array}{r}\text { Typhoon } \\
\text { Koppu }\end{array}$ & $\begin{array}{l}\text { Taxi not in operation, } \\
\text { waiting time }\end{array}$ & $\begin{array}{l}\text { About } 80 \% \text { of taxis were not in operation during the typhoon, } \\
\text { and the average customer-search time for drivers was very } \\
\text { short }\end{array}$ \\
\hline [14] & Taxi data & $\begin{array}{l}\text { New } \\
\text { York }\end{array}$ & $\begin{array}{l}\text { Hurricanes } \\
\text { Irene and } \\
\text { Sandy }\end{array}$ & Taxi ridership & $\begin{array}{l}\text { The hurricane has the greatest influence on the number of taxi } \\
\text { trips during weekend and at night, and the least impact on a } \\
\text { weekday during the day }\end{array}$ \\
\hline [15] & $\begin{array}{l}\text { Taxi and } \\
\text { metro } \\
\text { trips }\end{array}$ & $\begin{array}{l}\text { New } \\
\text { York }\end{array}$ & $\begin{array}{l}\text { Hurricanes } \\
\text { Irene and } \\
\text { Sandy }\end{array}$ & $\begin{array}{l}\text { Daily taxi trips, daily metro } \\
\text { ridership }\end{array}$ & $\begin{array}{l}\text { The recovery rate is lower for Sandy than that for Irene. A } \\
\text { higher resilience of road network when compared to the } \\
\text { metro network }\end{array}$ \\
\hline [16] & $\begin{array}{l}\text { Location } \\
\text { data }\end{array}$ & Shenzhen & $\begin{array}{l}\text { Typhoon } \\
\text { Mangkhut }\end{array}$ & Urban human flow & $\begin{array}{l}\text { Urban flows reduced by } 39 \% \text { during the disruption. } \\
\text { Fundamental urban functions experienced less disruption } \\
\text { and recreational related trips are more severely affected }\end{array}$ \\
\hline [17] & $\mathrm{AFC}$ data & Shenzhen & 5 typhoons & Metro ridership & $\begin{array}{l}\text { Typhoon events can severely influence the distributions and } \\
\text { recovery of metro ridership }\end{array}$ \\
\hline$[31]$ & Twitter & $\begin{array}{l}\text { New } \\
\text { York }\end{array}$ & $\begin{array}{l}\text { Hurricane } \\
\text { Sandy }\end{array}$ & $\begin{array}{l}\text { Shifting distance of the } \\
\text { center of mass } \\
\text { The radius of gyration }\end{array}$ & $\begin{array}{l}\text { During and after Hurricane Sandy, the human movements } \\
\text { followed truncated power-law distributions. Human } \\
\text { movements attained significant perturbations during } \\
\text { hurricane }\end{array}$ \\
\hline$[32]$ & Twitter & $\begin{array}{l}\text { New } \\
\text { York }\end{array}$ & $\begin{array}{l}\text { Hurricane } \\
\text { Sandy }\end{array}$ & $\begin{array}{l}\text { Travel distance, the radius } \\
\text { of gyration, and mobility } \\
\text { entropy }\end{array}$ & $\begin{array}{l}\text { The distance, radius and entropy of individuals decreased } \\
\text { significantly after Sandy. Individuals in higher } \\
\text { transportation diversity locations generally maintained a } \\
\text { higher distance and radius one week after Sandy }\end{array}$ \\
\hline$[33]$ & Twitter & The U.S. & $\begin{array}{l}\text { Hurricanes } \\
\text { Matthew, } \\
\text { Harvey }\end{array}$ & $\begin{array}{l}\text { Trip distance, radius of } \\
\text { gyration, and mean } \\
\text { square displacement }\end{array}$ & $\begin{array}{l}\text { Displacements become shorter and areas of activity become } \\
\text { smaller during hurricanes. The displacement follows the } \\
\text { power-law models }\end{array}$ \\
\hline$[34]$ & Twitter & $\begin{array}{l}\text { Over the } \\
\text { world }\end{array}$ & $\begin{array}{l}15 \text { Constructive } \\
\text { cases }\end{array}$ & $\begin{array}{l}\text { Displacement, the radius of } \\
\text { gyration }\end{array}$ & $\begin{array}{l}\text { In most cases, the power-law can explain human mobility in } \\
\text { most cases. The resilience has its limits and fails in more } \\
\text { powerful natural disasters }\end{array}$ \\
\hline$[35]$ & Twitter & 8 Areas & 5 Typhoons & $\begin{array}{l}\text { Displacement } \\
\text { The radius of gyration }\end{array}$ & $\begin{array}{l}\text { Human movements are significantly perturbed by typhoons } \\
\text { with different magnitudes in different cases, and follow } \\
\text { power-law distribution }\end{array}$ \\
\hline
\end{tabular}

Besides, when the investigation is conducted at the station level, it is helpful to cluster stations into certain types as the number of stations is large. Lv et al. [37] applied K-means clustering method to divide the metro stations into 3 types according to the passenger flows. Similarly, the K-means clustering method was applied to discern distinct metro station groups, which is further used to employ the geographically weighted regression model to examine the spatial variation of the built environment's impact on different types of metro stations [38]. Moreover, employing clustering method to detect different distinct ridership patterns of metro and taxi, Kim [39] identified influence factors on human mobility for each pattern depending on the modes of transportation in Seoul. Besides, Hyland et al. [40] first clustered public bike stations based on their trips using K-means clustering techniques. They highlighted that determinants of public bike station usage vary across station-clusters.

To summarize, recent researchers have paid attention to natural disasters' influence on traffic, such as traffic flow, taxi trip and public transit ridership. The number of taxi trips is widely used to explore the ridership changes during natural disasters. Besides, the metro ridership is also investigated at the system level. However, it lacks investigating the metro ridership changes during natural disasters at different levels, consisting of system, station, and origin-destination (OD) level. Besides, many researchers utilized the Twitter data and found that human movements are significantly perturbed by natural disasters with different magnitudes in different cases and follow power-law distribution. However, there are few studies about the human mobility in the metro system under natural disasters. Thus, we collected the transaction data before and during the typhoon weather event to explore the ridership changes, the relative total traveled stations changes and the differences of human mobility in different states, which can give some suggestions for further operation of metro system in response to extreme weather events. 


\section{Data Description}

This study is conducted in Fuzhou, which is the capital of Fujian province, China. The total land area of Fuzhou is 11,968 square kilometers, with 1786 square kilometers of urban area and 357 square kilometers of built-up area. In 2017, there were 7.7 million people in Fuzhou. Fuzhou has a typical subtropical monsoon climate with abundant sunshine and rainfall, with an average annual precipitation of 900-2100 $\mathrm{mm}$. In 2017, the average annual rainfall in Fuzhou was $1508.2 \mathrm{~mm}$. Affected by typhoons, the rainfall in Fuzhou reached $49.2 \mathrm{~mm}$ on July 30, 2017, and 102.7 $\mathrm{mm}$ on July 31, 2017. In addition, Fuzhou is a coastal city which is more likely to be affected by typhoons. Thus, it is meaningful to analyze the impacts of typhoon weather events on the metro system to improve the transit service.

On January 6, 2017, Line 1 in Fuzhou Metro was officially put into operation. Line 1 has a total length of 24.618 $\mathrm{km}$, with 21 stations, passing through the main urban area of Fuzhou. In 2017, the average daily ridership of Fuzhou Metro was about 135,000 . The station number and name in Line 1 of Fuzhou Metro are presented in Table 2.

Typhoon 9 (Typhoon Nesat) and Typhoon 10 (Tropical Storm Haitang) passed through on July 30 and 31, 2017, respectively. Based on the precipitation records, the hourly rainfall in the city during the typhoon weather events is presented in Fig. 1. Besides, July 30 and July 31 are Sunday and Monday, respectively. On July 30, the precipitation mainly happened during 4:00-11:00. While on July 31 , the precipitation last from 8:00 to 23:00, with two breaks.

As shown in Table 3, the transaction records include card ID, enter station, enter time, exit station, exit time. In this study, we focus on the changes of metro ridership and human mobility resulted from the typhoon weather events. Thus, all transaction data on Sundays and Mondays of July 2017 were selected for making comparison. Besides, the abnormal transaction records which enter and exit in the same station are removed. Finally, the total ridership of normal Mondays was 536,712, and that of normal Sundays was 459,774 . The metro ridership on July 30 was 68,779 and that on July 31 was 100,829 during typhoon weather events.

In addition, to measure the human mobility distribution, it is required to calculate the travel time of each trip [41]. With the transaction data of metro trips, the travel time of each trip can be calculated according to Eq. 1 .

$\Delta t=t_{\mathrm{d}}-t_{\mathrm{o}}$

where $\Delta t$ is the travel time, $t_{0}$ denotes the enter time in the origin station, and $t_{\mathrm{d}}$ denotes the exit time in the destination station.
Table 2 Station number and name in Line 1 of Fuzhou Metro.

\begin{tabular}{ll}
\hline Number & Name \\
\hline 1 & Xiangfeng Station \\
2 & Xiushan Station \\
3 & Luohanshan Station \\
4 & Fuzhou Railway Station \\
5 & Doumen Station \\
6 & Shudou Station \\
7 & Pingshan Station \\
8 & Dongjiekou Station \\
9 & Nanmendou Station \\
10 & Chating Station \\
11 & Dadao Station \\
12 & Shangteng Station \\
13 & Sanchajie Station \\
14 & Baihuting Station \\
15 & Huluzhen Station \\
16 & Huangshan Station \\
17 & Paixia Station \\
18 & Chengmen Station \\
19 & Sanjiaocheng Station \\
20 & Lulei Station \\
21 & Fuzhou South Railway Station \\
\hline &
\end{tabular}

Besides, the number of traveled stations is an important indicator, which is closely related to the total travel time and fare. Thus, this study also takes the number of traveled stations into consideration. The number of traveled stations for each trip can be calculated from the transaction data. Thus, the number of traveled stations is measured according to Eq. 2.

$\Delta s=\left|s_{\mathrm{d}}-s_{\mathrm{o}}\right|$

where $\Delta s$ is the number of traveled stations, $s_{0}$ means the origin station ID, and $s_{\mathrm{d}}$ denotes the destination station ID.

\section{Methodology}

\subsection{Assessment of Metro Ridership}

This study utilized the relative ridership to measure the perturbation resulted from the typhoon weather event [17]. This indicator can represent the difference between the disturbed and normal ridership. Rather than the absolute difference in ridership, which is affected by population, city size, and the scale of metro systems, the relative ridership can avoid their influences and can be applied for inter-city comparison. The relative ridership is computable, meaningful, and comparable. It was measured at three 


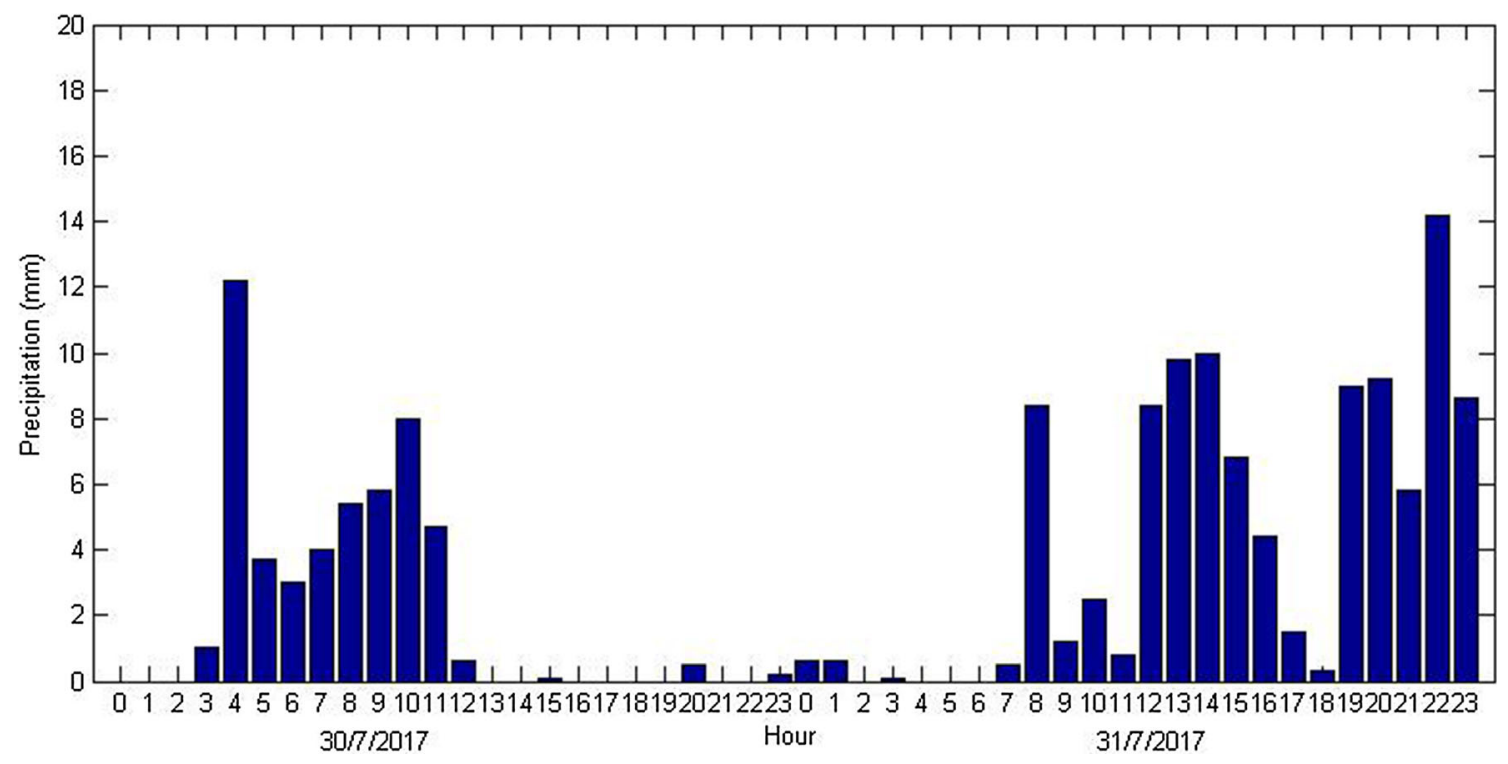

Fig. 1 The hourly precipitation during the typhoon weather events.

Table 3 Examples of transaction data in the metro system.

\begin{tabular}{lclll}
\hline Card ID & Enter station & Enter time & Exit station & Exit time \\
\hline 37225438293185000 & 3 & $2017073006: 34: 16$ & 4 & $2017073006: 38: 30$ \\
36108441729507300 & 4 & $2017073006: 43: 02$ & 5 & $2017073006: 50: 34$ \\
36108441726518500 & 1 & $2017073021: 59: 42$ & 8 & $2017073022: 19: 40$ \\
36108441856489200 & 3 & $2017073020: 33: 04$ & 8 & $2017073020: 45: 36$ \\
36108441594251000 & 4 & $2017073019: 22: 21$ & 9 & $2017073019: 36: 10$ \\
36099538926270200 & 11 & $2017073019: 09: 45$ & 21 & $2017073019: 37: 42$ \\
\hline
\end{tabular}

$\mathrm{TTS}=\sum_{i}^{I} \Delta s_{i}$

levels, including the system level, station level and origindestination level. In addition, the stations are classified by $K$-means clustering method according to the hourly ridership.

The relative ridership (see Eq. 3) is measured with the ridership on the normal days and that on the typhoon days.

$\mathrm{RR}_{\mathrm{t}}=\frac{r_{\mathrm{t} \_\mathrm{typ}}}{r_{\mathrm{t} \_ \text {nor }}}$

where $R_{t}$ is the relative ridership between ridership in typhoon days and that in normal days in time period $t$, $r_{\mathrm{t} \_ \text {nor }}$ means the ridership in time period $t$ of normal days, and $r_{\mathrm{t} \text { typ }}$ denotes the ridership in time period $t$ of typhoon days.

\subsection{Assessment of Total Traveled Stations}

The number of traveled stations is a useful metric to measure human mobility in the metro system [5]. It can not only reflect the ridership, but also show the traveled stations of each trip. With the traveled stations for each trip (see Eq. 2), the number of total traveled stations can be calculated based on Eq. 4. where TTS denotes the number of total traveled stations, $\Delta s_{i}$ is the number of traveled stations for trip $i, I$ is the number of metro trips.

The TTS for different situations can be computed from the corresponding transaction dataset. Furthermore, to reflect the deviation of TTS in typhoon weather event, this study adopts the average TTS of normal days as the baseline. With transaction data of the normal days in July 2017, TTS can be calculated as Eq. 5 .

$\overline{\mathrm{TTS}_{\mathrm{t}}}=\frac{1}{D} \sum_{d=1}^{D} \operatorname{TTS}_{\mathrm{t} d}$

where $\overline{\text { TTS }_{\mathrm{t}}}$ is the average TTS of time period $t, D$ is the number of normal days.

Based on $\mathrm{TTS}_{\mathrm{t}}$ of the typhoon weather event and the baseline $\overline{\mathrm{TTS}_{\mathrm{t}}}$, the relative total traveled stations (RTTS) is computed as Eq. 6. 
$\operatorname{RTTS}_{\mathrm{t}}=\frac{\operatorname{TTS}_{\mathrm{t}}}{\overline{\operatorname{TTS}_{\mathrm{t}}}}$

RTTS is a normalized metric which can measure the deviation of actual travels resulted from the typhoon weather event, compared with that in the normal state.

\subsection{K-Means Clustering Method}

$\mathrm{K}$-means clustering is an unsupervised learning method which can identify groups of objects that are similar to each other to attain distinct groups [39]. For the simplicity and power in high-dimensional space, $K$-means clustering has been applied in many fields [42-44]. $K$-means algorithm aims to divide $\mathrm{n}$ objects $\left(x_{i}, i=1, \ldots, n\right)$ into $k$ different clusters $\left(C=\left\{c_{1}, \ldots, c_{k}\right\}\right)$ according to the similarities of attributes [38]. The purpose of $K$-means is to minimize the distance of the objects within the same cluster and, in the meantime, maximize the distance between the clusters. The objective function of K-means clustering is as follows:

$F(C)=\sum_{j=1}^{k} \sum_{x_{i} \in c_{k}} d\left(x_{i}, \mu_{k}\right)$

where $x_{i}$ represents the value of object $i, \mu_{k}$ is the centroid of $c_{k}$, and $d\left(x_{i}, \mu_{k}\right)$ denotes a distance metric. In this study, the hourly entering ridership and the hourly exiting ridership are the adopted attributes for metro stations.

\subsection{Assessment of Human Mobility}

This study aims to utilize the travel time to explore human mobility in metro system and the impacts resulted from typhoon weather event. According to the previous study [29], model selection can determine the most proper model for experimental data from multiple models. This study utilizes the Akaike information criterion (AIC) to select the most proper model, which takes the optimal balance between the complexity and the description of the model [41]. It has the advantage of avoiding over-fitting. Besides, it can compare various models in the meantime and provide the most fitting model. In detail, the process of model selection is as follows: first, the parameters are estimated by the maximal likelihood estimation (MLE) for different models; second, each model's AIC score is calculated according to $\mathrm{AIC}_{i}=-2 \log L_{i}+2 K_{i}$ (where $L_{i}$ is the likelihood of the model $i$, and $K_{i}$ denotes the number of parameters in the model $i$ ) ; Finally, the Akaike weight is calculated as $W_{i}=e^{-\Delta_{i} / 2} / \sum_{j=1}^{N} e^{-\Delta_{j} / 2} \quad$ (where $\Delta_{i}=\mathrm{AIC}_{i}-\mathrm{AIC}_{\min }, \mathrm{AIC}_{\text {min }}=\min \mathrm{AIC}_{i}$, and $N$ is the number of the candidate models). Furthermore, the model with the largest Akaike weight is selected.
According to previous studies $[29,45]$, three candidate models, which are frequently used for human mobility in public transit, are compared in the study, consisting of Gamma, Weibull and lognormal distributions. The gamma distribution can be formatted as Eq. 8 .

$P(x)=\frac{1}{\theta^{k} \Gamma(k)} x^{k-1} e^{-x / \theta}$

where $k>0$ and $\theta>0$ are the shape parameter and scale parameter, respectively. Besides, $\Gamma()$ is the gamma function.

The Weibull distribution can be formatted as Equation 9.

$P(x)=\frac{a}{b}\left(\frac{x}{b}\right)^{a-1} e^{-(x / b)^{a}}$

where $a>0$ and $b>0$ are the shape parameter and scale parameter, respectively.

The lognormal distribution can be formatted as Eq. 10.

$P(x)=\frac{1}{x \sigma \sqrt{2 \pi}} \exp \left(-\frac{(\ln x-\mu)^{2}}{2 \sigma^{2}}\right)$

where $\mu$ and $\sigma$ are the mean and standard deviation of natural logarithm of the variable.

\section{Results and Analysis}

\subsection{System Level Ridership}

The daily ridership of Fuzhou Metro in different situations is calculated and presented in Table 4. On normal days, the ridership is higher on Monday than that on Sunday. As to the typhoon Sunday, the ridership is 0.60 as that on the normal Sunday. While on Monday, the extreme weather event leads to a reduction by $25 \%$ in metro ridership. It can be found that metro ridership is more seriously affected on Sunday. This is consistent with the fact that more travels on Mondays are commuting ones which are fixed demands and cannot be avoided. However, trips on Sundays are more likely to be leisure ones

Table 4 The average daily ridership of Fuzhou metro system.

\begin{tabular}{llll}
\hline Day & $\begin{array}{l}\text { Average daily } \\
\text { ridership of normal } \\
\text { day }\end{array}$ & $\begin{array}{l}\text { Average daily } \\
\text { ridership of typhoon } \\
\text { day }\end{array}$ & $\begin{array}{l}\text { Relative } \\
\text { ridership }\end{array}$ \\
\hline Sunday & 116,187 & 69,559 & 0.60 \\
Monday & 135,424 & 101,619 & 0.75 \\
\hline
\end{tabular}


Table 5 Station types by K-means clustering method.

\begin{tabular}{ll}
\hline Types & Stations \\
\hline Type 1(in residential areas) & $1,2,3,12,13,14$, \\
& $15,16,18,19,20$ \\
Type 2 (in office areas) & $5,7,10,11,17$ \\
Type 3 (in the areas of mixed land use) & $6,8,9$ \\
Type 4 (in transportation hubs) & 4,21 \\
\hline
\end{tabular}

In detail, the hourly riderships in normal weather and typhoon weather of Sunday are presented in Fig. 2, and those of Monday are presented in Fig. 3. Besides, the hourly relative ridership caused by the typhoon weather event is depicted in Fig. 4. According to Fig. 2, the hourly ridership on Sunday has apparent peaks during the morning and evening peak hours on the normal weather days. However, suffered from the typhoon weather event, the peak in the morning peak hours disappears, which is consistent with the heavy rain in the morning. In addition, the peak in the evening moves from 18:00 to 17:00. Similarly, the hourly ridership on Monday is plotted in Fig. 3. There are significant morning and evening peaks on both the normal weather and typhoon days. In general, the hourly ridership is less influenced on Monday.

As for the hourly relative ridership shown in Fig. 4, the relative ridership is extremely low during 8:00-11:00 on Sunday. This is consistent with the amount of hourly precipitation for the day, in which the rain is heavy in the morning. In the afternoon (13:00-17:00), the relative ridership is larger. While in the evening, there is also a lower relative ridership. For Monday, the relative ridership is large in the morning peak hours, with a value of 0.9 at 8:00. During 9:00-18:00, the relative ridership is stable, with a value about 0.75 . Besides, there is a smaller relative ridership in the evening.

\subsection{Station Level Ridership}

The system level ridership is a macroscopic indicator. Furthermore, we aim to analyze the station level ridership. With the hourly ridership of each station, this study applies $K$-means clustering method to cluster stations into 4 types for further analysis. The classification results are shown in Table 5.

The stations are classified into four types, and Type 1 owns 11 stations. The ridership patterns of four types are presented in Fig. 5. Stations of Type 1 are located in residential areas, with the obvious morning peak of entering passengers and evening peak of exiting passengers on Monday. Stations of Type 2 are located in the office areas with an obvious morning peak of exiting passengers and an evening peak of entering passengers on Monday. Stations of Type 3 are located in the areas of mixed land use. There are peaks for both entering and exiting passengers in the morning and evening in the stations of Type 3. Stations of Type 4 are located in transportation hubs, with fluctuating entering and exiting passengers.

The average station level ridership is calculated according to station types and the results are presented in Table 6 for further analysis. According to Table 6, Type 1 has the largest ridership on Monday, followed by Type 2 . Besides, Type 3 and Type 4 have a similar ridership on the normal Monday. On the normal Sunday, Types 1, 2, and 3 have significant decreases in ridership when compared with that on the normal Monday. On the contrary, the ridership of Type 4 is larger than that of the normal Monday.

As to the impacts of the typhoon weather event, Type 1 is most severely affected, with a relative ridership of 0.73 , and Type 3 is the least influenced one on Monday (0.79). On Sunday, Type 3 has the lowest relative ridership (0.59) and Type 4 has the biggest one (0.63). On typhoon days, residents will reduce unnecessary travel, which leads to a significant decline in ridership. It can be found that the average ridership of normal days is various for different station types, together with various values of relative ridership resulted from the typhoon weather event.

\subsection{OD Level Ridership}

Furthermore, we investigate the daily ridership of each station pair. The OD level ridership is defined as the daily metro ridership for each OD pair. The OD level ridership on the normal Sunday and Monday is presented in Fig. 6 and Fig. 7, respectively. The average OD level ridership on Sunday is 263. On Monday, the average OD level ridership is higher, with a value of 307 . For most OD pairs, the ridership is quite low. For Sunday, there are several OD pairs with higher ridership, such as $\operatorname{OD}(4,8), \operatorname{OD}(4,10)$, $\mathrm{OD}(8,4), \quad \mathrm{OD}(21,10)$ and $\mathrm{OD}(21,13)$. For Monday, $\mathrm{OD}(4,8), \mathrm{OD}(4,10), \mathrm{OD}(8,4), \mathrm{OD}(10,4)$ and $\mathrm{OD}(21,10)$ have higher ridership. Although the OD level ridership is lower on Sunday than that on Monday, the highest OD level ridership of Sunday is more than 2500, which is higher than the highest OD ridership (1827) of Monday. Overall, some OD pairs show higher values, while most OD pairs are low in ridership.

As the OD with small ridership is unstable and fluctuates greatly, we select OD pairs with more than 100 passengers on normal days to analyze the changes resulted from the typhoon weather event. Besides, the relative value between the ridership in typhoon weather event and that of normal days is set as 1 in this study for OD pairs with ridership less than 100 . 


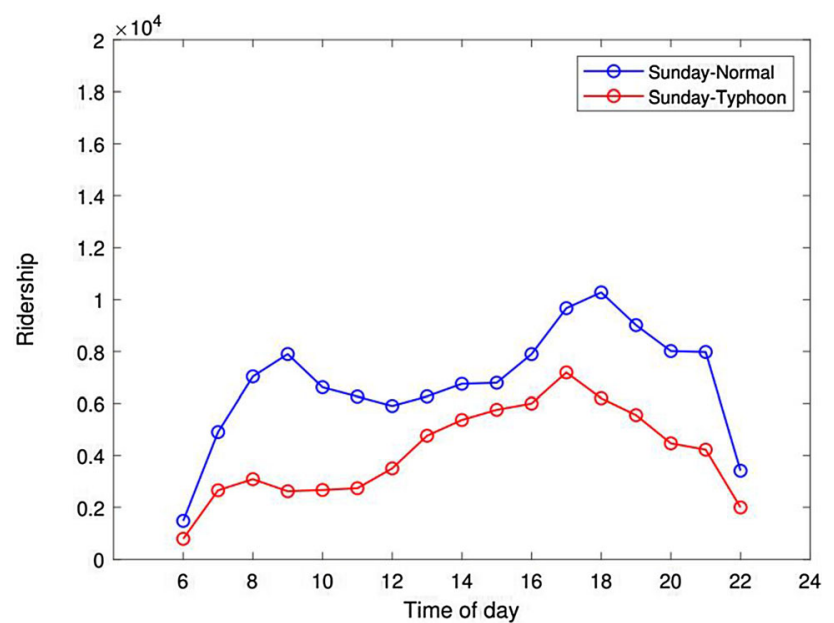

Fig. 2 The hourly ridership of metro system in normal weather and typoon weather on Sundays.

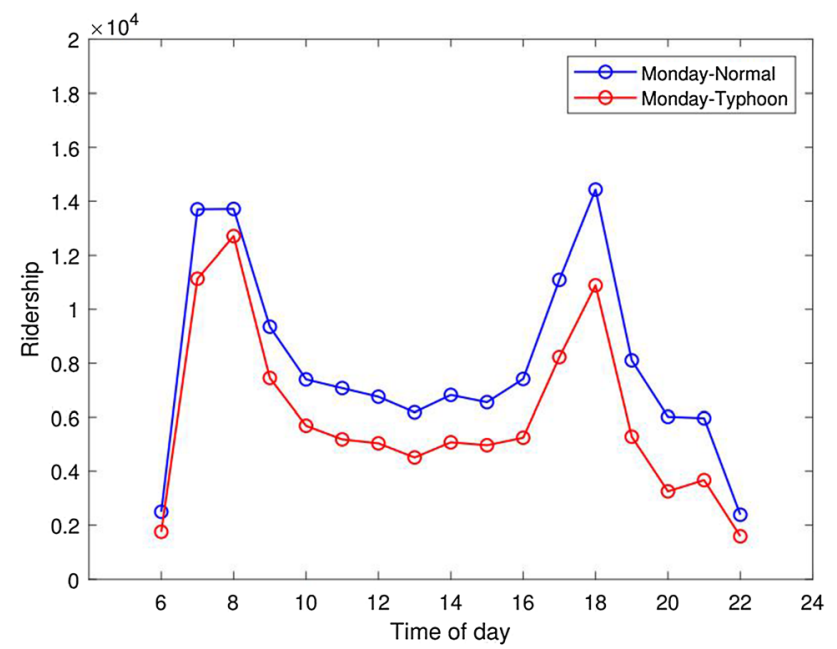

Fig. 3 The hourly ridership of metro system in normal weather and typoon weather on Mondays.

On Sunday, there are 153 OD pairs with less than 100 passengers on normal days, which are set as 1 in Fig. 8 and take $34.7 \%$ of all OD pairs. For the remaining OD pairs, most relative values are less than 1 , which indicates that the ridership on the typhoon day is less than that in normal days for OD pairs. On the contrary, the ridership of $\mathrm{OD}(4,21)$ and $\mathrm{OD}(14,16)$ in typhoon weather event has increased, compared to the ridership on the normal Sunday.

On Monday, there are 142 OD pairs with less than 100 passengers on the normal Monday, which are set as 1 in Fig. 9, taking $32.2 \%$ of all OD pairs. After removing these OD pairs, most OD pairs decreased in different magnitudes on the typhoon day. There are only several OD pairs, including $\mathrm{OD}(5,6), \mathrm{OD}(6,5), \mathrm{OD}(9,10)$, and $\mathrm{OD}(10,9)$, with higher ridership when compared to those of normal

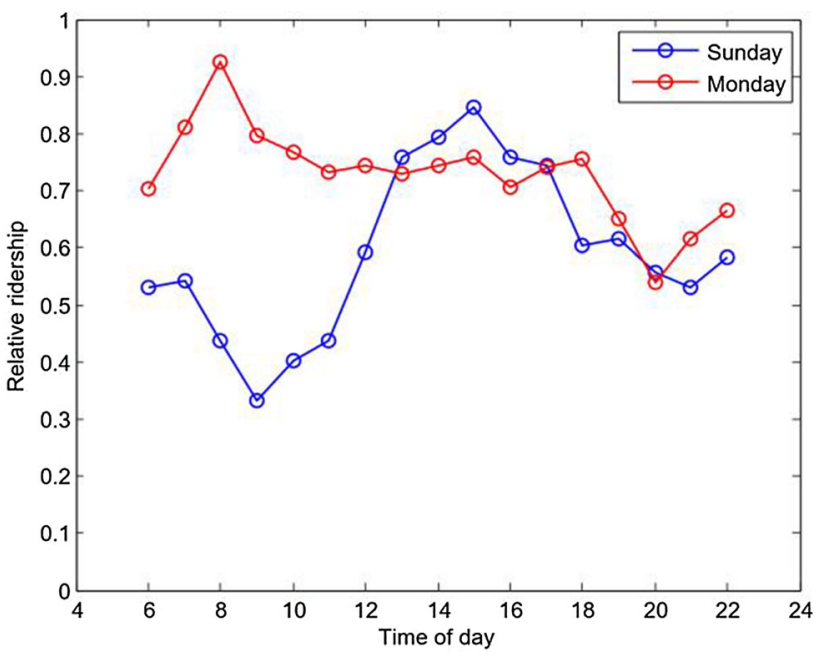

Fig. 4 The hourly relative ridership of metro system resulted from the typhoon weather events.

Table 6 The average daily ridership of different station types.

\begin{tabular}{lllll}
\hline & Type 1 & Type 2 & Type 3 & Type 4 \\
\hline Normal Monday & 91,089 & 69,056 & 44,188 & 42,584 \\
Typhoon Monday & 66,573 & 53,034 & 34,945 & 32,098 \\
Relative ridership & 0.73 & 0.77 & 0.79 & 0.75 \\
Normal Sunday & 76,867 & 51,439 & 30,644 & 50,492 \\
Typhoon Sunday & 46,794 & 30,742 & 18,130 & 31,587 \\
Relative ridership & 0.61 & 0.60 & 0.59 & 0.63 \\
\hline
\end{tabular}

Mondays. The changes of ridership between Station 3 and Station 14 in the urban area of Fuzhou are not significant, mostly between 0.7 and 1 . The residential areas and working places in this section are relatively dense, and the commuting by metro is rigid demand for these residents.

\subsection{Relative Total Traveled Stations}

The RTTS curves based on metro trips for the typhoon weather event on Sunday and Monday are presented in Fig. 10. On July 30, the rainstorm began at 3:00, which was earlier than the opening time of the metro system. Thus, the typhoon weather event had significant influences on human mobility in the metro system when it began to operate in the morning. During the typhoon weather event, the RTTS reached its bottom (0.35) around 9:00 on July 30 . According to Fig. 1, the rainstorm ended at 11:00. The RTTS saw an apparent increase and stay around 0.75 during 13:00-17:00. In the evening, the RTTS was about 0.50 although there was almost no precipitation. Besides, the average number of traveled stations is 6.68 on the normal Sunday, and it decreases to 6.55 on the typhoon Sunday. 

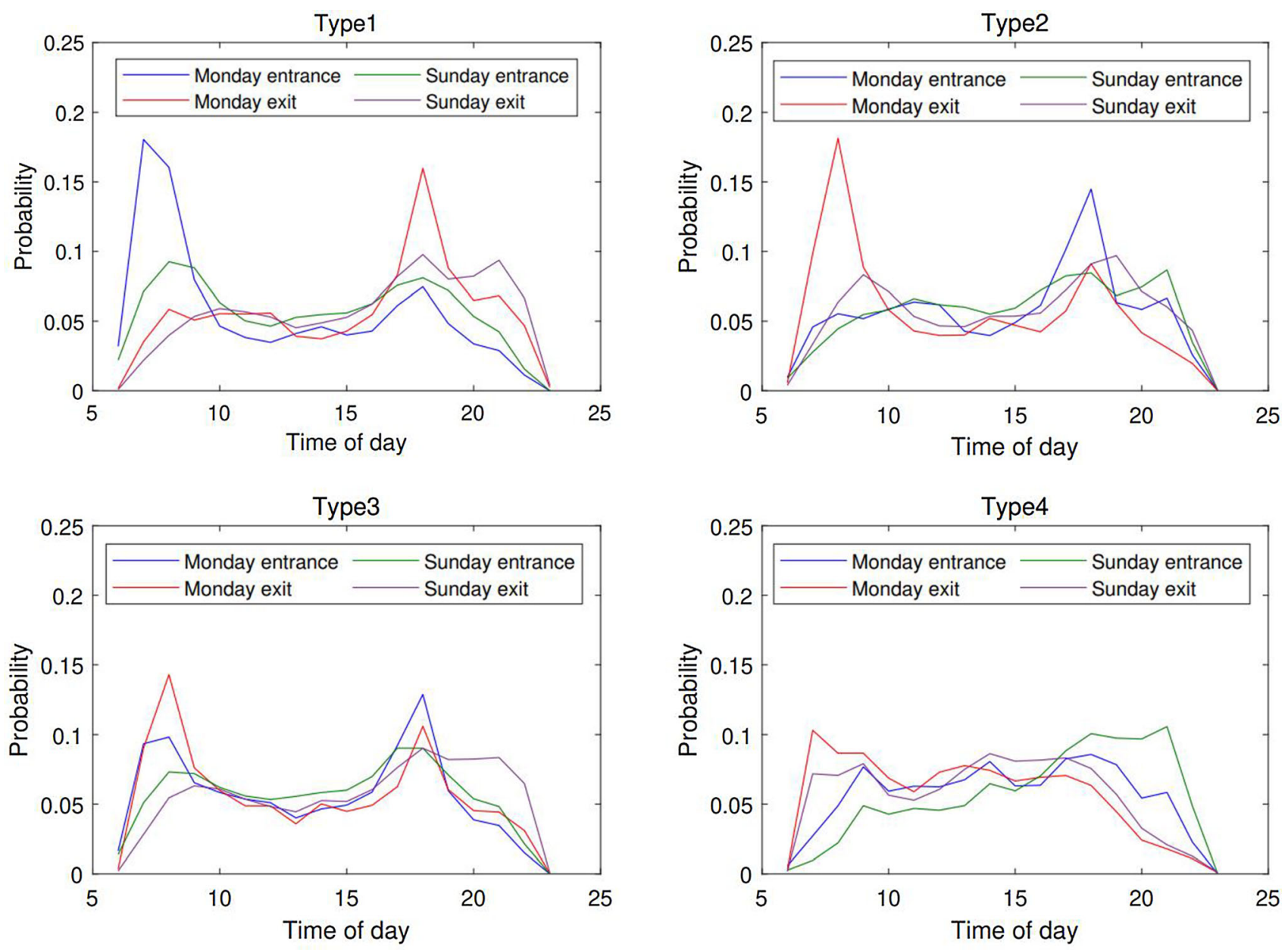

Fig. 5 The ridership pattern of four station types.
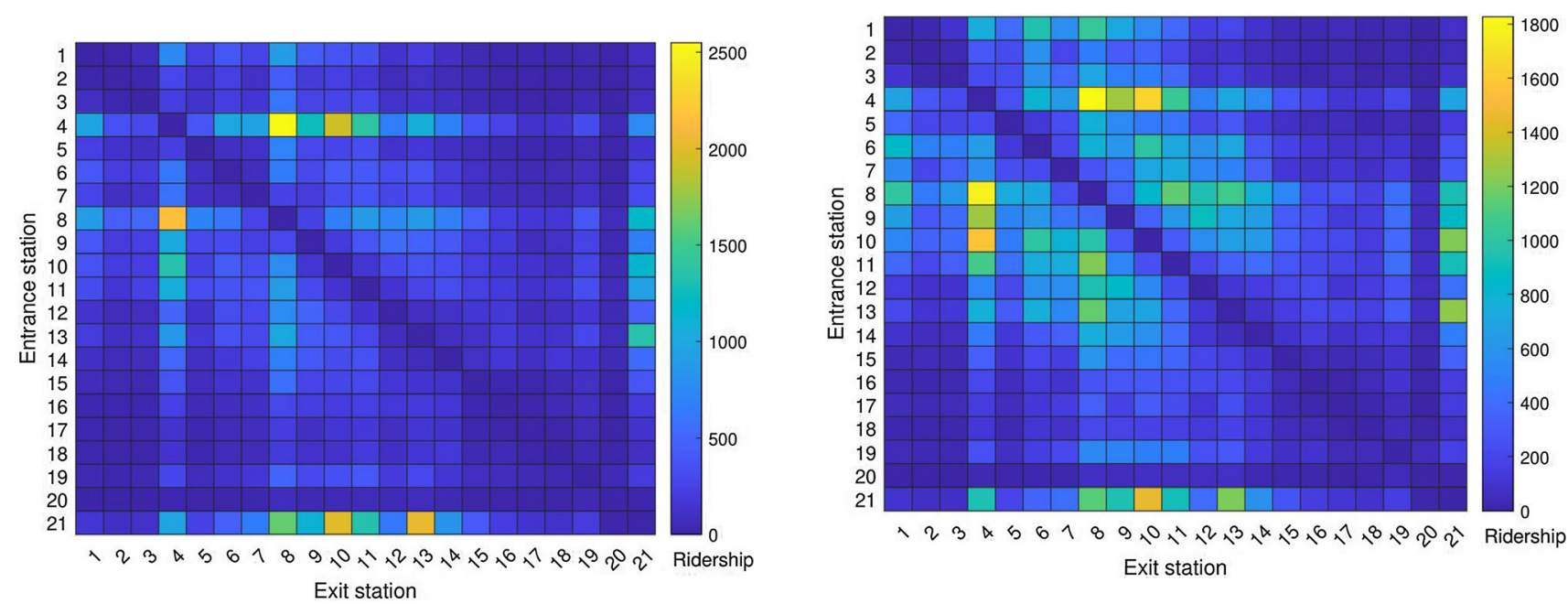

Fig. 6 The average daily OD ridership of normal Sunday.

On July 31, the RTTS curve showed a different pattern compared with that of July 30. At 8:00, the RTTS approached 0.89, which is resulted from the stable commuting trips. Besides, some passengers may switch from

Fig. 7 The average daily OD ridership of normal Monday.

car and bus to metro as it is less impacted by the extreme weather events. During 10:00-18:00, the RTTS was stable with a value around 0.72 . In addition, the RTTS reached its lowest value of July 31 at 20:00. As a whole, 


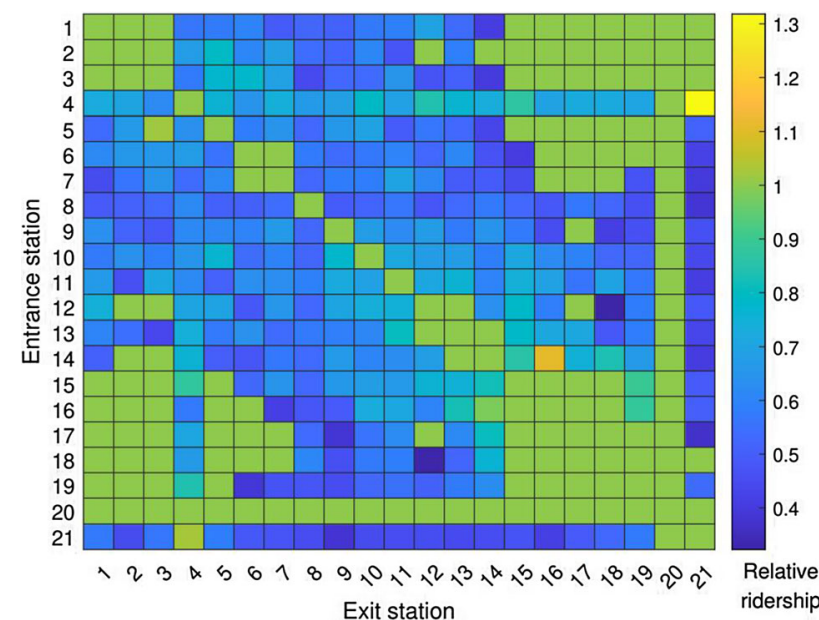

Fig. 8 The relative ridership between the typhoon day and the normal day in each OD pair on Sunday.

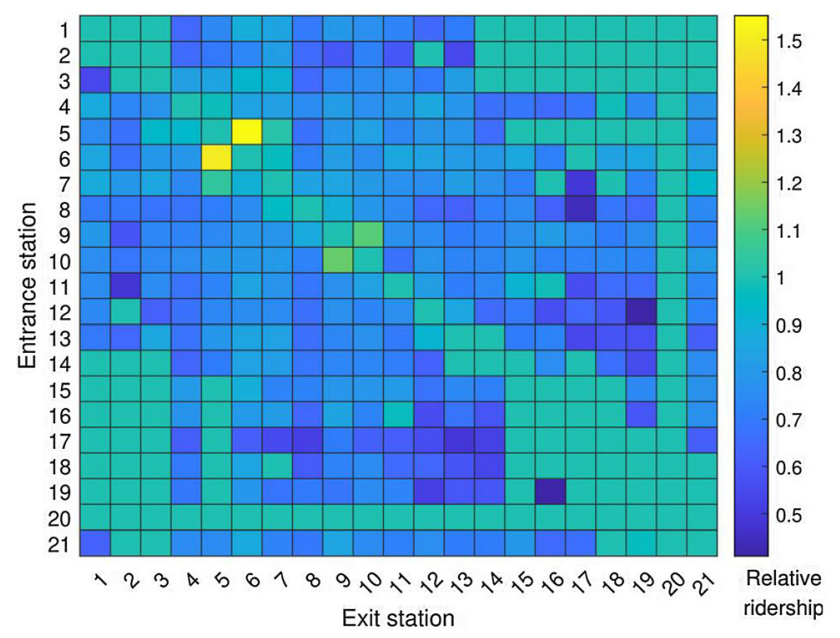

Fig. 9 The relative ridership between the typhoon day and the normal day in each OD pair on Monday.

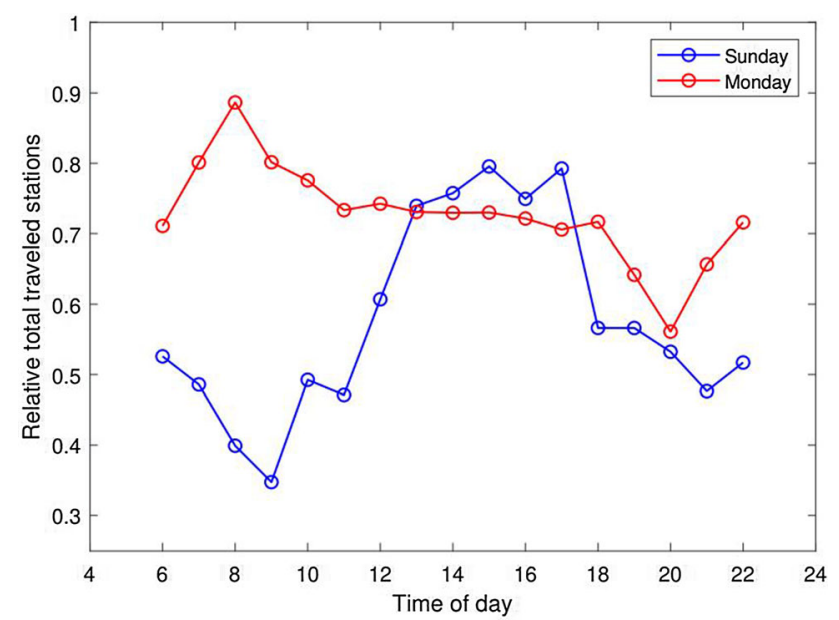

Fig. 10 The relative total traveled stations of metro trips during the typhoon weather events.

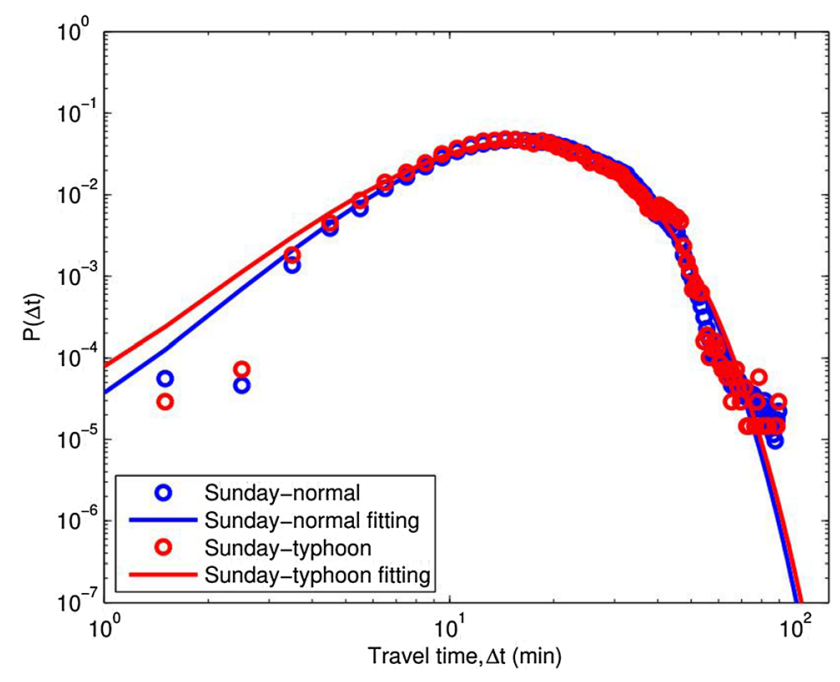

Fig. 11 The travel time distribution and gamma fitting on Sunday. The blue line indicates the gamma distribution of the normal Sunday $(k=5.0499, \theta=4.1388)$, and the red line denotes the gamma distribution of the typhoon Sunday $(k=4.6544, \theta=4.4390)$.

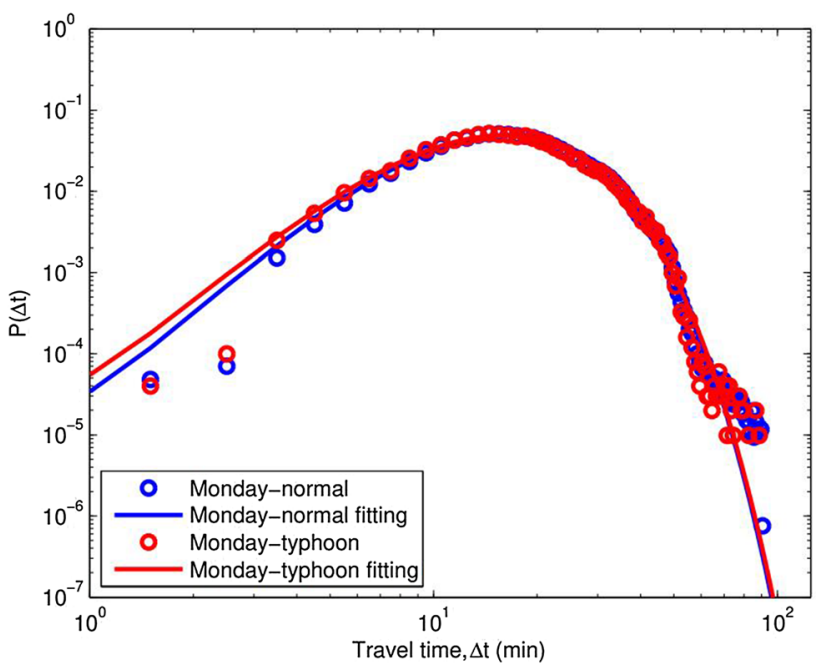

Fig. 12 The travel time distribution and the gamma fitting on Monday. The blue line indicates the gamma distribution of the normal Sunday $(k=5.2042, \theta=3.8770)$, and the red line denotes the gamma distribution of the typhoon Sunday $(k=4.9677, \theta=4.0020)$.

the average number of traveled stations is 6.22 on the normal Monday, and it decreases to 6.14 on the typhoon Monday.

According to RTTS in Fig. 10, there is a significant perturbation of human mobility in the typhoon weather event. The results showed that the human mobility was less impacted on Monday. It is indicated that commuting passengers have higher resilience to the typhoon weather event. 
Table 7 Results of model selection for travel time of metro trips in Fuzhou.

\begin{tabular}{llllll}
\hline Model & Item & Normal Sunday & Normal Monday & Typhoon Sunday & Typhoon Monday \\
\hline Gamma & MLE for $k$ & 5.0499 & 5.2042 & 4.6544 & 4.9677 \\
& MLE for $\theta$ & 4.1388 & 3.8770 & 4.4390 & 4.0020 \\
& $R_{\text {gam }}^{2}$ & 0.9972 & 0.9967 & 0.9936 & 0.9967 \\
& $W_{\text {gam }}$ & 1 & 1 & 1 & 1 \\
Weibull & MLE for $a$ & 23.6269 & 22.8061 & 23.3906 & 22.4856 \\
& MLE for $b$ & 2.3826 & 2.3832 & 2.2748 & 2.3451 \\
& $R_{w b l}^{2}$ & 0.9750 & 0.9962 & 0.9945 & 0.9683 \\
& $W_{w b l}$ & 0 & 0 & 0 & 0 \\
Lognormal & MLE for $\mu$ & 2.9375 & 2.9054 & 2.9170 & 2.8857 \\
& MLE for $\sigma$ & 0.4668 & 0.4569 & 0.4855 & 0.4691 \\
& $R_{\operatorname{logn}}^{2}$ & 0.9926 & 0.9961 & 0.9947 & 0.9944 \\
& $W_{\operatorname{logn}}$ & 0 & 0 & 0 & 0 \\
\hline
\end{tabular}

\subsection{Human Mobility in Travel Time}

Travel time distribution can describe human mobility in the metro system in detail. Thus, this study fits the travel time distribution of Fuzhou Metro before and during the typhoon weather event. The travel time of each metro trip is computed from the transaction data. The distribution of travel time on Sunday is presented in Fig. 11. As a whole, the travel time of trips averages at $21.13 \mathrm{~min}$ on the normal Sunday. In addition, the probability increases firstly and reaches the peak when the travel time is about $18 \mathrm{~min}$. Then, the probability decreases with the increase in travel time. On the typhoon Sunday, the peak of the probability curve moves from $18 \mathrm{~min}$ to $17 \mathrm{~min}$. Besides, the travel time of trips averages at $20.66 \mathrm{~min}$ on the typhoon Sunday. According to the actual data, the probability of the typhoon Sunday is higher in the first range. In the middle range, the normal Sunday has higher probability.

The travel time distributions of Monday are provided in Fig. 12. Overall, there are similar characteristics as those in Fig. 11. On the normal Monday, the probability increases firstly and reaches the peak when the travel time is about 16 min. Then, the probability decreases with the increase in travel time. On the typhoon Monday, the peak of the probability curve moves from 16 to $15 \mathrm{~min}$. The travel time of metro trips averages at 20.24 min on the normal Monday and at $19.88 \mathrm{~min}$ on the typhoon Monday.

According to the data, this study fits the travel time with three candidate models, including Gamma, Weibull, and lognormal distributions. Besides, we applied AIC method to compare the three models and select the most fitting one. The results of model selection are provided in Table 7 . According to the Akaike weight of three candidate models in Table 7, the gamma distribution fits the four datasets better than other models, with different values in parameters. On both Sunday and Monday, the typhoon days have a smaller shape parameter $(k)$ and a larger scale parameter $(\theta)$ than the normal days. Besides, in the normal and perturbed state, Monday has a larger shape parameter $(k)$ and a smaller scale parameter $(\theta)$ when compared to Sunday. Lastly, the fitted gamma distributions are presented in Figs. 11 and 12.

\section{Conclusions and Future Work}

This paper conducted a case study which aimed to examine the ridership and human mobility perturbation in the metro system during the typhoon weather event. The findings indicate that the metro system attains an apparent impact in ridership due to the typhoon weather event, with larger decrease for Sunday and smaller decrease for Monday. On the typhoon Sunday, the ridership decreases most in the morning when the rainstorm is heavy. A similar decrease can be seen in the evening of Monday with the typhoon weather event.

This study employed the K-means clustering method to classify metro stations into 4 types with different travel patterns. The results confirm that the four types of stations are influenced with different degrees with their characteristics. For OD level ridership, most OD pairs see significant ridership decreases with the impacts of the typhoon weather event. However, several OD pairs attain increase in ridership. This can be attributed to the fact that many passengers may switch from other modes to metro, as it is less affected by typhoon than other modes. For the RTTS, it is lower for the leisure trips, such as trips on Sunday and trips in the evening of Monday. The average number of traveled stations is larger on Sunday when compared to that on Monday. Besides, the average number of traveled stations is smaller in the typhoon state than that in the normal state on Sunday and Monday. 
As to the human mobility in terms of travel time, the travel time is lower in the typhoon event than that in the normal state. We compare three candidate models, including Gamma, Weibull, and lognormal distribution, with the Akaike information criterion to select the more fitting one. The gamma distribution is the most fitting one for travel time of metro trips in the four situations with different values of parameters. On both Sunday and Monday, the typhoon days have a smaller shape parameter $(k)$ and a larger scale parameter $(\theta)$ than the normal days. Besides, in the normal and perturbed state, Monday has a larger shape parameter $(k)$ and a smaller scale parameter $(\theta)$ when compared to Sunday. It can be concluded that travel time distributions are significantly perturbed by typhoons, and follow gamma distribution.

The findings from this study have practical implications for metro management under extreme weather events. With a deeper understanding of perturbation to ridership at different levels and human mobility of different states in the metro system, it is helpful for decision-makers to take proper strategies to mitigate the impacts and damages from typhoon.

Besides, there are some limitations in this study. This paper only takes one case into consideration; thus, it is difficult to measure the first typhoon's impacts on the second day. It is better to consider the impact of extreme weather events in Fuzhou in the long-term and compare the impacts of different cities to conclude more general findings. Although this study analyzes metro ridership of two days which are Sunday(weekend) and Monday (weekday) respectively, and passengers have different travel patterns naturally. Finally, another potential issue is to measure the potential effects of excessively severe flood on stations and the access modes and the contribute to the changes of travel behaviors.

Acknowledgements This study has been presented in 2021 TRB Annual Meeting.

Funding This work was supported by the National Natural Science Foundation of China (Grant 61976055).

\section{Declarations}

Competing interests The authors declare that they have no conflict of interest.

Open Access This article is licensed under a Creative Commons Attribution 4.0 International License, which permits use, sharing, adaptation, distribution and reproduction in any medium or format, as long as you give appropriate credit to the original author(s) and the source, provide a link to the Creative Commons licence, and indicate if changes were made. The images or other third party material in this article are included in the article's Creative Commons licence, unless indicated otherwise in a credit line to the material. If material is not included in the article's Creative Commons licence and your intended use is not permitted by statutory regulation or exceeds the permitted use, you will need to obtain permission directly from the copyright holder. To view a copy of this licence, visit http://creativecommons. org/licenses/by/4.0/.

\section{References}

1. Zhou M et al (2017) Impacts of weather on public transport ridership: results from mining data from different sources. Transp Res Part C Emerg Technol 75:17-29

2. Jain D, Singh S (2021) Adaptation of trips by metro rail users at two stations in extreme weather conditions: Delhi. Urban Climate 36:100766

3. Ngo NS (2019) Urban bus ridership, income, and extreme weather events. Transp Res Part D Transp Environ 77:464-475

4. Wang $\mathrm{Y}$ et al (2017) Aggregated responses of human mobility to severe winter storms: an empirical study. PLoS ONE 12(12): 0188734

5. Zhang F et al (2019) Assessment of urban human mobility perturbation under extreme weather events: a case study in Nanjing, China. Sustain Cities Soc 50:101671

6. Lin P et al (2020) Impact of weather conditions and built environment on public bikesharing trips in Beijing. Netw Spat Econ 20(1):1-17

7. Yang B et al (2020) Soft-mobility in a winter-dominant city: a case study by comparing nordic and non-nordic residents in Umeå. Cities 102:102727

8. Bocker L, Dijst M, Prillwitz J (2013) Impact of everyday weather on individual daily travel behaviours in perspective: a literature review. Transp Rev 33(1):71-91

9. Liu C, Susilo YO, Karlstr M (2017) Weather variability and travel behavior: What we know and what we do not know? Transp Rev 2017:1-27

10. Abad RPB, Fillone AM (2020) Changes in travel behavior during flood events in relation to transport modes: the case of Metro Manila, Philippines. Transp Res Procedia 48:1592-1604

11. Abad RPB, Schwanen T, Fillone AM (2020) Commuting behavior adaptation to flooding: an analysis of transit users' choices in Metro Manila. Travel Behav Soc 18:46-57

12. Lyu H-M et al (2019) Flood risk assessment of metro systems in a subsiding environment using the interval FAHP-FCA approach. Sustain Cities Soc 50:101682

13. Wong RCP et al (2021) Spatio-temporal influence of extreme weather on a taxi market. Transp Res Rec J Transp Res Board 2675(9):639-651

14. Bian R, Wilmot CG, Wang L (2019) Estimating spatio-temporal variations of taxi ridership caused by Hurricanes Irene and Sandy: a case study of New York City. Transp Res Part D Transp Environ 77:627-638

15. Zhu Y et al (2016) Using big data to study resilience of taxi and subway trips for hurricanes sandy and Irene. Transp Res Rec J Transp Res Board 2599(1):70-80

16. Chen $Z$ et al (2020) Impact of extreme weather events on urban human flow: a perspective from location-based service data. Comput Environ Urban Syst 83:101520

17. Zhou Y et al (2021) Analyzing spatio-temporal impacts of extreme rainfall events on metro ridership characteristics. Physica A Stat Mech Appl 577:126053

18. Liu K, Murayama Y, Ichinose T (2021) Exploring the relationship between functional urban polycentricity and the regional characteristics of human mobility: a multi-view analysis in the Tokyo metropolitan area. Cities 111:103109

19. Vittoria Corazza M et al (2021) Chronicles from the New Normal: urban planning, mobility and land-use management in the 
face of the COVID-19 crisis. Transp Res Interdiscip Perspect 2021:100503

20. Barbosa $\mathrm{H}$ et al (2018) Human mobility: models and applications. Phys Rep 734(734):1-74

21. Song $\mathrm{C}$ et al (2010) Limits of predictability in human mobility. Science 327(5968):1018-1021

22. Kraemer M et al (2020) Mapping global variation in human mobility. Nat Hum Behav 4:800-810

23. Hu S et al (2021) Examining spatiotemporal evolution of racial/ ethnic disparities in human mobility and COVID-19 health outcomes: evidence from the contiguous United States. Sustain Cities Soc 76:103506

24. Orak NH, Ozdemir O (2021) The impacts of COVID-19 lockdown on PM10 and SO2 concentrations and association with human mobility across Turkey. Environ Res 197:111018

25. Benita F (2021) Human mobility behavior in COVID-19: a systematic literature review and bibliometric analysis. Sustain Cities Soc 70:102916

26. González M, Hidalgo CA, Barabási A (2009) Understanding individual human mobility patterns. Nature 453:779-782

27. Wang W et al (2015) A comparative analysis of intra-city human mobility by taxi. Physica A 420:134-147

28. Yao C, Lin J (2016) A study of human mobility behavior dynamics: a perspective of a single vehicle with taxi. Transp Res Part A Policy Practice 87:51-58

29. Jiang $S$ et al (2017) Human mobility in space from three modes of public transportation. Physica A 483:227-238

30. Huang F et al (2019) A movement model for air passengers based on trip purpose. Physica A 525:798-808

31. Wang Q, Taylor JE (2014) Quantitying human mobility perturbation and resilience in hurricane sandy. PLOS ONE 11(9):e112608

32. Rahimi-Golkhandan A, Garvin MJ (2021) Assessing the impact of transportation diversity on post-disaster intra-urban mobility. J Manag Eng 37(1):04020106

33. Ahmouda A, Hochmair HH, Cvetojevic S (2019) Using Twitter to analyze the effect of hurricanes on human mobility patterns. Urban Sci 3(87):1-20
34. Wang Q, Taylor JE (2016) Patterns and limitations of urban human mobility resilience under the influence of multiple types of natural disaster. PLoS ONE 11(1):e0147299

35. Wang Q, Taylor JE (2015) Resilience of human mobility under the influence of typhoons. Procedia Eng 118:942-949

36. Wang Y, Taylor JE (2018) Coupling sentiment and human mobility in natural disasters: a Twitter-based study of the 2014 South Napa Earthquake. Nat Hazards 92(2):907-925

37. Lv Y et al (2021) Mobility pattern recognition based prediction for the subway station related bike-sharing trips. Transp Res Part C Emerg Technol 133:103404

38. Li S et al (2020) Spatially varying impacts of built environment factors on rail transit ridership at station level: a case study in Guangzhou, China. J Transp Geogr 82:102631

39. Kim K (2018) Exploring the difference between ridership patterns of subway and taxi: case study in Seoul. J Transp Geogr 66:213-223

40. Hyland $\mathrm{M}$ et al (2018) Hybrid cluster-regression approach to model bikeshare station usage. Transp Res Part A Policy Practice 115:71-89

41. Liang $X$ et al (2012) The scaling of human mobility by taxis is exponential. Physica A 391(5):2135-2144

42. Douzas G, Bacao F, Last F (2018) Improving imbalanced learning through a heuristic oversampling method based on k-means and SMOTE. Inf Sci 465:1-20

43. Ahmed N (2015) Recent review on image clustering. IET Image Proc 9(11):1020-1032

44. Adnan RM et al (2021) Prediction of hydraulics performance in drain envelopes using K-means based multivariate adaptive regression spline. Appl Soft Comput 100:107008

45. Wang MS et al (2012) Exploring the mobility patterns of public transport passengers. J Univ Electron Sci Technol China 41(1):2-7 